\title{
PHILOSOPHIA DO DIREITO
}

\section{A arte, a sciencia e a philosophia do direito}

E' classica a divisão da sciencia do direito em dogmatica juridica, historia de direito e philosophia do direito.

Reproduzindo essa divisão, Roussel define a dogmatica juridica: a parte da sciencia do direito, que tem por objecto o direito positivo, considerado em sua formação, interpretação, applicação e execução (I). Depois de observar que o direito póde ser estudado como direito positivo, ou existente em um dado momento, no seu desenvolvimento historico e sob o aspecto ideal, GiUdice affirma que são tres as formas essenciaes da sciencia do direito: a dogmatica, a historica e a philosophica (2) Filomusi Guelfi por sua vez acceita a commum divisão, e define o que denomina "a sciencia do direito positivo": um systema de conhecimentos relativos ao direito positivo (3). De accordo com os juristas citados estão, em geral, os autores de encyclopedias juridicas e de tractados de philosophia do direito.

(1) Encyclopédie du Droit. § 98.

(2) Enciclopedia Giuridica, § 24.

(3) Enciclopedia Giuridica, § 33. 
Sómente pelo cégo empirismo e pelos arraigados preconceitos, que por tantos seculos têm dominado a intelligencia dos cultores do direito, incapazes por sua falta de preparo scientifico de formar um conceito exacto ácerca da natureza da sciencia, podemos hoje explicar o absurdo da inclusão da dogmatica juridica entre as sciencias, ou da sua qualificação como ramo da sciencia do direito.

A dogmatica juridica, muito claramente o indica a propria expressão, tem por objecto o dogma do direito, isto é, os canones, as regras do direito positivo, as leis (no sentido technico, especial, do termo), escriptas ou consuctudinarias. Mas, as regras do direito são preceitos artisticos, normas para fins praticos, determinações, ordens, que se impõem á vontade. Não se confundem com as affirmações scientificas, que se dirigem á intelligencia. E' uma verdade de ordem didactica, evidente e corriqueira, a que ensina Stuart Mill no Systema de Logica: tudo o que se exprime por meio de regras, ou normas, formuladas para a realisação de actos com um fim util, pertence ao dominio da arte, assim como pertence ao dominio da sciencia tudo o que se exprime por meio de asserções geraes ácerca dos factos, de proposiçoes em que se enunciam as relações necessarias de successão, de coexistencia, ou de similhança, entre os phenomenos. Um codigo, ou qualquer lei extravagante, encerra uma série de preceitos, impostos á actividade voluntaria do homem, injuncções pelas quaes se ordena que se faça, ou deixe de fazer, alguma coisa. Investigar como se formou uma lei (na accepção technica, ou como expressão synonyma de norma), para bem lhe apprehender o sentido, afim de applical-a convenientemente, em toda a sua pureza, de perfeita conformidade com o pensamento e a vontade do legislador, nunca se poderá dizer uma funç̧ão da sciencia, 
mas apenas um trabalho artistico. Bem se comprehende quanto é exacta esta affirmação, quando se attende a que, mesmo na hypothese de verificar que nenhum fundamento tem o preceito juridico, e apenas exprime um preconceito da épocha, ou um erro do legislador a respeito de uma clada necessidade social, ao interprete, que deve dirimir as lides judiciaes, não é licito deixar de applicar a norma vigente, para proceder de accordo com as mais seguras pesquizas scientificas, concernentes ás condições reaes de vida e desenvolvimento da sociedade. Mais claramente ainda se vê o caracter artistico da dogmatica juridica, desde que se lembrem os dois methodos applicaveis, e geralmente applicados, ao estudo e ao ensino do direito positivo: o exegetico e o systematico, ou synthetico. São processos logicos artisticos, destinados a clescobrir e explanar o pensamento e a vontade do legislador, o que elle, bem ou mal, com ou sem fundamento scientifico, quer que se faça, a revelar o exacto sentido da $l e i$, na accepção technica do termo, e não a descobrir connexões necessarias entre os factos sociaes, relações causaes entre antecedentes e consequentes, ou leis, no sentido geral e scientifico da palavra. Pela exegese, que a principio revestia a 'forma e a denominação de glosa, e que hoje se chama commentario, procuramos conhecer o sentido da lez, seguindo a ordem estabelecida na mesma lei (4). Para conseguirmos esse fim, estudamos a significação dos termos, de que se serviu o legislador (elemento grammatical); analysamos as idéas contidas na lei, conciliando umas com as outras, e fazendo de todas ellas um conjuncto harmonico e bem comprehensivel (elemento logico); investigamos o estado do direico, ao tempo em que a lei foi promulgada, e os factos historicos que determi-

(4) Filomusi Guelfi, obra citada, § 34 . 
naram a formulação do novo preceito (elemento historico); tendo em attenção, afinal, o conjuncto das instituições e regras juridicas, vigentes no paiz, relacionamos a lei com todas as demais normas do direito, subordinando-a ao systema geral da legislação (elemento systematico). Todo esse vasto trabalho mental tem um fim util: reconstruir o pensamento do legislador; para bem applicar a lei, para cumprir a determinação, para obedecer á vontade do legisladır. Em taes esforcos nada ha de cummum com a tarefa da sciencia, que é observar os factos para formular as leis, isto é, as rela'ç̃os necessarias, derivadas da natureza das coisas. Adoptando o methodo systematico, distribuimos logicamente as varias instituições de direito; e, partindo das idéas geraes, que dominam o direito positivo de um dado paiz, em uma determinada épocha, expomos as normas juridicas positivas, as regras formuladas para a pratica, filiando os preceitos particulares aos preceitos geraes. Ainda aqui tẹmos uma exhibição de canones, uma explanação systematica de determinações, de ordens, impostas á vontade, e não de verdades geraes, de connexões necessarias entre os factos, de leis-no sentido scientifico da expressão.

O que talvez: tenha feito confundir a dogmatica juridica com a sciencia do direito, é o facto de não raras vezes esclarecer o jurista, e fundamentar, as normas de direito por meio de algumas verdades geraes, induzidas da observação dos factos sociaes. Ha na dogmatica juridica doutrinas, que á primeira vista pódem parecer theorias scientificas. Taes são, por exemplo, a doutrina da ignorancia e do erro de direito, a da retroactividade das leis e a da efficacia das leis no espaço. Um pouco de attenção, entretanto, e uma ligeira analyse serão sufficientes para patentear 
que, mesmo nestes casos em que "mais facil é confundir a arte do direito com a sciencia juridica, nada mais se nos depara que explanações artisticas. $\mathrm{O}$ preceito fundamental da primeira das doutrinas assignaladas é que a ignorancia e o erro de direito não devem. ser escusados, não merecem desculpa, não isentam a quem infringe as normas juridicas das consequencias da infraç̧ão. Esse preceito fundamental exprime apenas uma determinação do legislador. Que importa que tal preceito tenha por base a utilidade, ou, melhor, a necessidade social? Os preceitos de todas as artes, quer as bellas artes, como a architectura, a esculptura, a pintura, a musica, quer as artes liberaes, como a medicina, a engenharia, a advocacia, quer as industriaes, como a agricultura, as manufacturas, a metallurgia e a industria pastoril, assentam em verdades scientificas, em principios e suas deducções. A cada passo estão os artifices, os industriaes e os artistas, applicando regras, baseadas em conhecimentos da mechanica, da physica, da chimica, da biologiä, da anatomia, da physiologia. Os artistas que não se guiam pelas verdades da sciencia, bem merecem a candente censura com que Stuart Mrll estigmatisou os tacticos allemães da antiga escóla, derrotados por $\mathrm{NA}_{\mathrm{A}}$ POLEÃO I. ${ }^{\circ}$, porque se obstináram em applicar as regras obsoletas da sua arte céga, sem base na observação dos factos. Na doutrina da não retroactividade das leis, vemos a regra geral de não terem as leis effeito retroactivo, e as excepções a essa regra, uma e outras estabelecidas pelo legislador-como determinações impostas á nossa vontade, canones de applicação pratica para a consecução de certos fins de ordem social. A doutrina da efficacia da lei no espaço começa pela norma geral de que a lei é por sua natureza territorial, deve imperar no territorio do Estado, para em seguida expôr as innumeras excep- 
ções a essa regra. Eis ao que se reduzem as principaes doutrinas da dogmatica juridica.

A dogmatica juridica encerra um conjuncto de preçeitos, formulados para a realisação de fins determinados; é a explanação de uma arte. Confundil-a com a sciencia importa desconhecer um dos mais vulgares elementos da logica.

Tambem não é uma sciencia a historia do direito, como não é sciencia a historia geral, ou qualquer historia especial. Tãc absurdo é dar á historia a qualificação de sciencia, como denominar sciencia a estatistica.

A historia do direito (recordamos a definição de RousSEL) consiste na exposição das manifestações do direitı) sob todas as fórmas, nas diversas épochas e nos varios paizes, da successão das tradições juridicas, da origem e progresso das instituições existentes, dos costumes e das leis successivas a que a humanidade tem obedecido, e da sciencia do direito. Duas partes, como se vê, comprehende a historia do direito. $\mathrm{Na}$ primeira se relatam os preceitos de direito, as instituições positivas, os costumes e as leis, ou, por outras palavras, se contém a narração das regras artisticas, das normas de conducta, que regeram a actividade voluntaria do homein no passado. $\mathrm{Na}$ segunda se nos offerece um quadro das doutrinas, erroneas ou verdadeiras, ou em parte verdadeiras e em parte erroneas, com que os jurisconsultos e os philosophos procuráram explicar os phenomenos juridicos. Sendo assim, é evidente que a historia do direito sómente contém materiaes para as inducções da philosophia do direito. Se ás narrativas das instituições do passado se mesclam accidentalmente algumas generalisações, essas inducções, formuladas pelos historiadores do direito, pertencem ao dominio da philosophia do direito, 
ou, quando são verdades particulares, e não principios, ao dominio da sciencia do direito.

Com muita clareza e precisão expõe Roberty (5 a funcção, que desempenha a historia, de preparar os elementos necessarios para as generalisações das sciencias sociaes. A historia collecciona e dispõe methodicamente os materiaes, os factos, em cujo estudo e comparação diversas sciencias haurem suas inducções. O methodo descriptivo, applicado pelo historiador, é um excellente instrumento para a acquisição de verdades geraes da sociologia e das sciencias sociaes especiaes. Sem a observação não se dá um passo na formação de qualquer sciencia; a observação é a base commum do methodo de todas as sciencias; mas, cada uma destas tem o seu modo especial de observar. Ha sciencias que observam, por assim dizer, por uma simples intuição. Sẩo as mathematicas, que facilmente formulam e verificam as suas generalisações por meio de experiencias ideaes, como diz BAIN, repetidas illimitadamente em muito curto espaço de tempo, graças á facilidade com que representamos em nossa imaginação as grandesas e as fórmas. Muitas verdades mathematicas, geralmente reputadas axiomaticas ou aprioristicas, não passam de inducções dessas repetidas experiencias ideaes. Outras sciencias observam, no rigoroso sentido da expressão: tal é a astronomia. Outras recorremá experimentação, propriamente dita, provocam em dadas condições a reproducção do phenomeno que pretendem estudar: tal é a chimica. Outras, finalmente, para se constituirem, valem-se do methodo descriptivo: taes são a sociologia e as sciencias sociaes particulares. $\mathrm{O}$ methodo descriptivo, peculiar ás sciencias biologicas e sociaes, é ainda uma modalidade especial da observação, uma observação.

(5) La Sociologie, cap. 2. . 
"tran formada ou prolongada». A natureza especial dos phenomenos sociaes, que se colleccionam com grandes difficulclades, e que só quando reunidos em grandes massas permittem generalisações seguras, exige uma elaboração intermedia entre a mera observação e colleccionação dos factos e os ultimos esforços da analyse, da abstraç̧ão e da comparação, que geram as inducções, ou nos dão as leis, o que ha de commum, de constante e necessario, na realisação dos phenomenos. A historia não é uma sciencia, como não é sciencia a estatistica. Não passam ambas de exposições methodicas de factos.

As normas de conducta, os preceitos artisticos, impostos pela sanç̧ão material do Estado, não pódem deixar de ter por base verdades scientificas. Todas as artes desenvolvidas assentam em verdades geraes. O legislador não promulga as normas juridicas por sua alta recreação. Obriga o indıviduo a praticar certos actos, e a abster-se de outros, ou permitte que os membros da sociedade procedam cle certo modo, limitando a actividade voluntaria de todos, porque verifica pela observação dos factos que ha acções e omissões, dependentes da vontade humana, que são condições de vida e desenvolvimento da sociedade e dos seus membros. Aqui passamos para o dominio da sciencia, podemos observar os factos sociaes, e formular as leis a que estão subordinados, determinar o que ha de constante e necessario na sua producção. Ainda ninguem com maior clareza do que Novicow (6), nem com tanta vivacidade de expressão, logrou dar uma idéa exacta do que é a sciencia do direito, demonstrar que os factos de ordem juridica estão sujeitos a leis, no sentido em que o termo é empregado pelos cultores de todas as sciencias: Resumiremos os

(6) La Justice et l'Expansion de la Vie, cap. 1.ค, Paris, 1905. 
exemplos de Novicow, que lançam muita luz sobre este ronto. Imaginemos um individuo são e robusto, capaz de, em um só dia, como carregador, transportar doze objectos, ou, como mensageiro, levar doze mensagens, recebendo de cada vez um franco. Uma lei do paiz the cerceia a liberdade de locomoção, ou a de trabalho, e esse individuo, que trabalhava durante toda a semana para si, só póde trabạlhar quatro dias na semana. A principio ganhava I 2 francos por dia, ou 72 por semana; a lei o reduz a ganhar os 12 francos sómente em quatro dias por semana, ou 48 francos no correr da semana. Supponhamos que, em vez de ser tolhido na sua actividade pela lei, esse mesmo individuo quebre a perna, e, ficando coxo, se veja forçado a fazer 4 fretes por dia, ou 48 por semana. Num e noutro caso, quer em consequencia da promulgação da lei, que lhe tolheu a liberdade da locomoção ou a de trabalho, quer em consequencia do accidente, que o deixou aleijado, a posição economica do individuo figurado é a mesma. Em ambas as hypotheses se lhe reduz uma condição de desenvolvimento. Um oleiro póde fabricar 72 vasos por semana, e vender cada um por um franco. Em virtude de uma nova tarifa da alfandega, que facilita a importação da mercadoria por elle fabricada, sómente consegue vender 48 vasos por semana. Supponhamos que, em vez da nova tarifa, se tenham cortado ao oleiro tres dedos de uma das mãos, de modo que elle só possa fabricar 48 vasos por semana. $O$ resultado economico, num e noutro caso, é perfeitamente o mesmo: restringe-se-lhe uma condição de manutenção e de desenvolvimento. Um professor póde dar 6 lições por dia, e ganhar 360 francos por semana. O governo julga sobversivas as idéas do professor, e véda-lhe o ensino nos estabelecimentos publicos, pelo que o reduz a ganhar com lições particulares apenas i 80 francos por semana. Se, em vez dessa 
perseguição, uma molestia nervosa tivesse impossibilitado o professor de dar mais de 3 lições, as mesmas 3 lições que lhe são permittidas no magisterio particular, depois que o governo the prohibiu o ensino nos estabelecimentos publicos, o resultado seria identico. Extinguir, ou cercear, um diveito equivale a uma amputafão. Cada injustiça produz o effeito de limitar, ou extinguir, as condifões de vida, ou de desenvolvimento, do indivĩduo. E não é só o individuo que soffre a injustiça, quem fica mutilado, ou privado de uma condição de vida, ou de desenvolvimento. Tambem aquelle que inflige a injustiça, que desrespeita o direito, ou promulga uma lei contraria ás exigencias da natureza do homem, ou da sociedade, soffre as consequencias do acto injusto. Se o homem vivesse isolado, fóra da sociedade, não soffreria os effeitos, não sentiria as consequencias das injustiças feitas aos seus similhantes. Vivendo necessariamente no ambiente social, o homem tanto soffre uma reducção, ou extinç̧ão, conforme a gravidade da injustiça, nas suas condições de vida ou de desenvolvimento, quando infringe uma norma juridica, ou promulga uma lei contraria ás verdadeiras necessidades da sociedade e do individuo, como no caso de ser elle a victima da injustiça. Praticar um acto injusto é tão prejudicial como soffrer uma injustiça. Figuremos um individuo, que pelo seu trabalho diario ganhava io francos. Com esses io francos pódia adquirir io utilidades, produzidas pelos seus consociados. Por circumstancias extraordinarias; todos os membros do grupo do individuo supposto são atacados de paralysia nos braços. Por mais que trabalhe e produza, 0 individuo, que ganhava io francos diariamente, nada poderá adquirir, não mais satisfará as necessidades, que habitualmente satisfasia, com as ro utilidades que conseguia pela troca, directa ou indirecta. $O$ seu 
trabalho não lhe dá resultado algum. $O$ facto de ficarem impossibilitados de trabalhar os consociados do individuo imaginado, acarreta a este as mesmas consequencias que the traria o facto de ficar elle proprio impossibilitado de trabalhar. A um operario tanto faz ter uma molestia, que lhe véde completamente o trabalho, como trabalhar, receber o producto do trabalho, e não achar no mercado nenhuma das coisas de que precisa para a satisfacção de suas necessidades. Supponhamos que, em vez de serem atacados de paralysia nos braços, os consociados do individuo que figuramos, perdessem os braços em consequencia de um crime perpetrado por esse mesmo individuo, ficando assim impossibilitados de trabalhar, e portanto de permutar os seus productos pelos do individuo imaginado. $\mathrm{O}$ resultado seria exactamente o mesmo que no caso da paralysia: o crime produziria para o criminoso as mesmas consequencias más que elle sentiria, se fosse a victima. Imaginemos ainda uma sociedade, na qual o conjuncto das idéas seja egual a I Ooo, e as idéas produzidas pelo trabatho intellectual de cada anno em numero de ioo. No fim do primeiro anno terá esse grupo social I Ioo idéas. Por meio de leis vexatorias para a liberdade de pensamento, o governo embaraça a manifestação das idéas, e no fim do segundo anno, em vez de I 200 idéas, só ha no ambiente social i I 50. O resultado é perfeitamente o mesmo que se alcançaria por meio da ablação de certos lobulos cerebraes de alguns homens intelligentes. $\mathrm{E}$ os membros do governo, que pelo processo despotico da suppressão, ou cerceamento, da liberdade de pensamento, obstasse ao progresso intellectual, soffreriam tanto as más consequencias da mutilação por elles praticada, como se uma enfermidade, ou uma operação cirurgica, lhes houvesse reduzido a potencia intellectual. 
Para que a sociedade se conserve e progrida, é necessario delimitar harmonicamente a actividade voluntaria dos individuos e a da propria sociedade, representada por seus orgams. Essa restriç̧ão das actividades voluntarias é uma necessidade organica da sociedade, conhecida pela observação dos factos. Sem ella os membros do todo e este não têm as condições da vida e desenvolvimento, que dependem da vontade humana. A sciencia do direito, pois, para nos dar a theoria verdadeira ácerca da restriç̧ão das actividades voluntarias, precisa de estudar as condições de vida e desenvolvimento do individuo e da sociedade, o que póde fazer, estudando os factos e induzindo, ou deduzindo essas condições das sciencias que estudam especialmente o homem e a sociedade. Um tal estudo é perfeitamente scientifico. Procuramos depois conhecer as relações necessarias, derivadas da natureza das coisas, entre a conducta humana, ou os actos voluntarios, e a conservação e desenvolvimento da vida individual e social. Verificadas taes relações, o legislador pelo methodo teleologico tracta de obter a pratica dos actos voluntarios, necessarios para a conservação e progresso da collectividade e dos seus membros, isto é, formula os preceitos, as regras praticas, garantidas em sua observancia pela sancção material, ou força physica, de que dispõe o Estado. Ainda aqui o legislador se utilisa de conhecimentos scientificos; pois, é pela observaçã̃o dos factos psychicos que chega á conclusão de ser possivel obrigar o homem a realisar, ou deixar de realisar, certos actos pela comminação das penas e promessa das recompensas (determinismo psychico), e á conclusão de, por não ser sempre efficaz a coação psychica, se fazer necessario recorrer á coação mechanica, tambem applicada pelo Estado.

Conhecimentos verdadeiros e certos ácerca das necessidades bio-ethicas (necessidades da vida, de or- 
dem moral) do homem na sociedade, isto é, um conceito exacto sobre os direitos, podemos obter pelos processos logicos indicados. A conservação da vida depende de duas ordens de condições: de factos involuntarios, por exemplo-a ausencia de molestias e de accidentes, e de factos voluntarios, a ausencia de actos humanos, que de qualquer, modo perturbem, reduzam, ou extingam, a vida. Para evitar as molestias, applica o homem os preceitos hygienicos, baseados em inducções scientificas, e para cural:as os preceitos da therapeutica, que tambem têm por base verdades scientificas. Para evitar os actos voluntarios, perniciosos á vida social, ou para restaurar a saúde e a harmonia da sociedade, quando lesadas por esses actos, applica os preceitos do direito. Os homens presam a vida, consideram-na um grande bem; e por isso o Estado, verificando quaes são as condições voluntarias, actos positivos e negativos, de que dependem a conservação e o respeito da vida, véda a pratica dos actos contrarios, e ordena a dos actos favoraveis ao fim collimado. Não se limita o Estado a punir as aggressões e violencias; tambem condemna a falsificação dos alimentos, a negligencia das precauções hygienicas, todos os actos, dependentes da vontade, em summa, que podem lesar a vida. Ahi temos preceitos artisticos, baseados em observações scientificas, a arte do direito, fundada na sciencia do direito. A liberdade de movimentos physicos e a liberdade de manifestação das idéas, está provado pela observação historica e directa, são condições indispensaveis de conservação e progresso para o individuo e a sociedade: eis uma verdade scientifica. De accordo com essa verdade scientifica se formulam regras conducentes a adstringir os homens, pela coaç̧ão psychica e mechanica, ás ações e omissões necessarias para que se respeitem a liberdade de movimen- 
tos physicos e a de manifestação dos pensamentos. Para progredir, tem o homem necessidade de unir seus esforços aos de seus similhantes, de se associar; pois, muitas coisas uteis não póde conseguir pelos esforços individuaes unicamente. Sobre mais essa verdade scientifica estabelece regras de conducta, tendentes a garantir, pelos meios juridicos de que dispõe o Éstado, o direito de associação. $O$ uso e o goso das coisas materiaes e a permuta de serviços são outras necessidades humanas, conhecidas pela mais superficial observação dos factos. Dahi os preceitos artisticos, tendentes a garantir o uso e o goso das coisas materiaes e a permuta dos serviços.

Sendo assim, à sciencia do direito, sciencia que ainda hoje não é objecto de nenhuma explanação em obras destinadas a este. fim especial, e cujas idéas vemos esparsas nos livros de philosophia do direito, nos proprios tractados de dogmatica juridica e nos relatorios e discursos dos parlamentos, é a sciencia que tem por objecto o conjuncto organico das condifóes de vida e desenvolvimento do individuo e da sociedadie, dependentes da vontade humana, que convem garanitir pela forsa coercitiva do Estado.

Esta sciencia tem seus primeiros principios, suas idéas fundamentaes, cuja exposição constitúe a płzilosophia do direito.

De tres partes distinctas se compõe a philosophia do direito. Em primeiro logar, a philosophia do direito, parte distincta, mas não separada, da sciencia do direito, synthese final desta sciencia, estuda o methodo applicavel ás investigações scientificas do direito. A' philosophia de uma sciencia é que compete indicar o methodo por que deve ser estudada essa sciencia (7), ou a sua logica.

(7) Stuart MiLr, Augusto Comto e o Positivismo, pag. 54, da trad. de Clémenacéau, ed. de Paris, 1879 
Do methodo adoptado depende a direç̧ão do nosso espirito na formação de uma theoria scientifica. $\mathrm{Na}$ philosophia do direito, mais do que em qualquer outra doutrina, vê-se claramente quanto é exacta esta ultima affirmação. Se adoptarmos o methodo deductivo dogmatico, que parte de idéas geraes, ministradas pela fé religiosa, ou o methodo deductivo metaphysico, que parte de idéas geraes, dadas pela razão, qual a concebem os metaphysicos, a doutrina philosophica ácerca do direito, que formularmos, será radicalmente diversa da doutrina baseada no methodo scientifico. A logica de uma sciencia, à averiguação do methodo proprio para nos dar conhecimentos verdadeiros e certos sobre uma determinada série de phenomenos, compõe-se de conceitos geraes e fundamentaes ácerca da mesma sciencia; e, pois, faz parte da sua philosophia.

Em segundo logar, é funç̧ão da philosophia do direito expôr systematicamente os principios fundamentaes do direito. A sciencia juridica se divide em varios ramos. Temos o direito privado, que se occupa das relações juridicas que interessam principal, directa e immediatamente, ao individuo, e mediata e indirectamente á sociedade, direito privado que se subdivide em varias partes. Temos o direito publico, que se occupa das condições de vida e desenvolvimento que interessam directa, principal e immediatamente, á sociedade, e indirecta e mediatamente ao individuo, direito publico geralmente dividido em constitucional, administrativo, judiciario e penal. Temos ainda o direito internacional, que se occupa directa e immediatamente das condições de existencia e progresso dos Estados, e mediata e indirectamente das dos individuos. O estudo de cada um desses ramos da sciencia juridica, feito parcial ou isoladamente, não nos leva á exacta comprehensão da sciencia do direito. 


\section{$-47-$}

Precisamos de relacionar os principios desses varios ramos da sciencia juridica, vêr as dependencias em que se acham uns em relação aos outros, para formarmos uma doutrina que abranja a sciencia do direito em toda a sua vastidão. E' assim que conseguimos descobrir os traços de união entre todos esses diversos ramos da sciencia do direito, o que ha de commum, de geral, em todos elles, unificando todo o saber juridico. O que é o direito em geral, em toda a sua extensão; que factos, ou que principios, explicam a existencia do direito; qual a sùa funç̧ão; quaes os seus fins: eis alguns assumptos geraes, que não são objecto de explicação para nenhum dos ramos da sciencia juridica, e que entram no quadro da philosophia do direito.

A quem estude separadamente as subdivisões do direito privado e os diversos ramos do direito publico, podem passar despercebidas as relações de dependencia entre um e outro. Entretanto, o estudo systematico do direito logo nos revela que o Estado é um presupposto necessario do direito, o organismo que faz valer o direito. A exacta interpretação das necessidades sociaes do dominio do direito privado depende da organisação conveniente dos poderes do Estado. A sciencia e à arte que têm por objecto a genese, ou formação, a essencia, os limites e o exercicio, dos poderes publicos, isto é, o direito constitucional, se nos apresenta assim na mais estreita relação com o direito civil. O direito administrativo, que comprehende a coordenação de todos os ramos da administração publica e todos os serviços publicos, desempenhados pelo Estado; ou pelos seus sub-organismos, bem como os postos sob a sua direç̧ão, tutela, ou fiscalisação, e o direito judiciario, que constitue os 
juizos, singulares ou collectivos, $\epsilon$ determina as normas de proceder perante elles, por sua vez se nos revelam desenvolvimentos logicos do direito constitucional. No direito penal se nos depara um reforço de garantia das normas dos varios ramos de direito: já que a nullidade dos actos, praticados contra a disposição da lei, a execução judicial, a indemnisação dos prejuizos soffridos, todas as sanções; em summa, dos outros ramos do direito não são sufficientes em face da gravidade do mal causado e da temibilidade do infractor da norma juridica, addiciona-se ás sancções dos outros ramos do direito esta sanç̧ão mais efficaz - a pena.

Mas, com a determinação das relações, dos diversos ramos do direito entre si, e com a coordenação das idéas fundamentaes de todos elles, formandose por esse processo uma doutrina systematica dos principios do direito, não está concluida a missão da philosophia do direito. Para bem explicar os factos juridicos, para aprofundar quanto possivel a sciencia do direito e offerecer uma série de fecundas indicações ac legislador, ainda cumpre estudar as relações do direito com as sciencias que têm por objecto o homem e a sociedade, isto é, com ás sciencias anthropologicas e sociaes.

No estudo das condições de vida e desenvolvimento do individuo e da sociedade, estudo indispensavel para a formação de uma theoria verdadeira ácerca da limitação harmonica das actividades voluntarias, precisamos de recorrer aos ensinamentos da physiologia, da anatomia, da pathologia, da psychologia, da psychiatria, da sociologia, da economia politica, sob pena de, não o fazendo, constituirmos uma theoria erronea, que leve o legislador a estabelecer preceitos contrarios ás verdadeiras necessidades e exigencias da collectividade e dos seus membros. 
Mas, objectar-se-á talvez: nesse caso vimos a ter a a sciencia do direito formada com um amalgama de conhecimentos do dominio de varias outras sciencias, o que importa não termos uma verdadeira sciencia do direito. Tal objecção só poderia partir de quem não attentasse no modo como se têm constituido todas as sciencias, inclusive as sciencias inferiores, menos complexas. Recordemos um exemplo, o de uma sciencia inquestionavelmente tida como tal, e das mais adeantadas e seguras. Em que consiste a astronomia? Como se adquire o conhecimento do conjuncto dos astros? Pelos phenomenos geometricos, mechanicos, physicos e chimicos (8). Depois de resumir algumas das principaes verdades do dominio da astronomia, conclúe Bresson: "Tal é o conjuncto dos principaes meios de investigaçãe de que dispõe a astronomia, meios que se tomam emprestados a todas as sciencias, desde as mathematicas puras até á physica e á chimica» A materia organica, e com ella o organismo, estão sujeitos a leis mechanicas, physicas e chimicas, que estudamos na biologia. Os orgams da visão e da audição são verdadeiros apparelhos de physica. O conhecimento do homem, physico e psychico, e o do meio em que elle vive, constitúem o ponto de paŕtida obrigatorio dos estudos sociologicos. Ora, esses conhecimentos nos são fornecidos, no que toca ao homem, pela biologia e pela psychologia, e, no que diz respeito ao meio, pela astronomia e pelas sciencias physico-chimicas. Nada mais natural, pois, do que formarmos a theoria scientifica do direito, utilisando-nos de noções das sciencias anthropologicas e sociaes. ICILIO VANNI definiu a philosophia do direito: "a sciencia que, ao mesmo tempo que integra as scien-

(8) Vide a este respeito BRESSON - Les Trois Evolutions, $\$ \S 61$ e sèguintes. 
cias juridicas na unidade dos seus principios mais geraes, liga o direito á ordem universal, com a qual o relaciona, para lhe explicar a formação historica na sociedade humana, e investigar-]he sob o aspecto ethico as exigencias racionaes" (9). Ha na definição transcripta uma parte verdadeira, e por todos acceita: a philosophia do direito coordena e integra os diversos ramos da sciencia juridica, offerecendo-nos uma exposição systematica dos principios, das idéas mais geraes, do direito. Mas, a asserção de que o direito se liga á ordem universal (vestigio da definição de Ahrens), embora contenha um residuo de verdade, é tão vaga, que quasi nada nos esclarece ácerca da natureza do direito. Onde a definição se desvia completamente dos preceitos logicos e das exigencias scientificas, é na parte final, em que se nos apresenta como funç̧ão da philosophia do direito investigar sob o aspecto ethico as exigencias racionaes do direito. Além de não ser comprehensivel a investigação das exigencias do direito sob o aspecto da moral, quando na commum opinião as verdades juridicas são uma parte das verdades ethicas, é absolutamente inacceitavel essa tarefa, assignada á philosophia do direito, de indagar quaes as exigéncias racionaes do direito. Só para quem adopte o mèthodo dos racionalistas, e como base do direito ponha as idéas congenitas, os principios absolutos da razão, é admissivel esse criterio indeterminado, indefinivel, vago, sem nenhum fundamento scientifico, nem utilidade pratica, das exigencias racionaes para aquilatar as verdades juridicas.

A definição de Cogliolo: - "a doutrina que estuda as leis mais, geraes $e$ as causas mais remotas das 1906.

(9) Lezioni di Filosofia del Diritto, cap. II, pag. 19, Bolonha, 
instituifões juridicas" (ı o), é demasiadamente laconica. Contém a parte verdadeira, commum a todas as escolas e doutrinas: a philosophia do direito tem por objecto as leis mais geraes, as verdades fundamentaes, os principios da sciencia do direito. Procura conhecer, não ha duvida, as causas mais remotas das instituições juridicas. Mas, porque não orientar aos que desejam conhecer precisamente o conteúdo da philosophia do direito, pela indicação, ao menos, da natureza dessas causas remotas, das doutrinas onde podemos descobril-as?

Mais approximada da verdade nos parece a definição de PUGLIA: "a sciencia que coordena e integra as idéas fundamentaes das varias sciencias juridicas particulares, e ao mesmo tempo as relaciona com as sciencias anthropologicas e sociaes" ( I I). Nesta definição só falta incluir a parte methodologica, parte capital, da philosophia do direito. Omittil-a equivale a dar uma idéa deficiente do objecto definido; porquanto, a parte fundamental da philosophia do direito, a de que dependem os principios que se hão de expôr, e o conhecimento das relações do direito com as outras sciencias, ou, se quizerem acompanhar a ICILIO VANNI, as relações do direito com a ordem universal, é exactamente a relativa ao methodo applicavel ao estudo do direito.

Tendo em attenção as ponderações feitas, podemos definir a philosophia do direito, dizendo que é a parte geral da sciencia juridica, que determina o methodo applicavel ao estudo scientifico do diveito, expóe systematicamente os principios fundamentaes dos varios ramos do saber juridico, e ensina as relafões deste com as sciencias anthropologicas e sociaes.

(10) Filosofia del Diritti Privato, cap. $10^{\circ}$

(11) Saggi di Filosofia Giuridica, pag. 62, Napoles, 1885. 
O unico methodo applicavel á formação da sciencia do direito é o positivo, ou scientifico, combinação dos processos inductivos com a deducção. Os outros processos logicos, outr'ora constantemente empregados no estudo do direito, hoje só merecem attenção como parte interessante da historia do direito.

Graças ao methodo positivo, já se têm fixado com segurança algüns conceitos fundamentaes da sciencia juridica, e entre estes o primeiro principio do direito, a necessidade social, organica, da limitação proporcionada das actividades voluntarias, principio dado pela sociologia, que verifica essa necessaria condição elementar da vida collectiva nas proprias sociedades animaes.

O que mais se faz mistér para o progresso do direito, e para a formação de normas juridicas de accordo com as verdadeiras necessidades e exigencias da naturesa individual do homem e da sociedade, é o desenvolvimento das sciencias anthropologicas e sociaes. Bem conhecer a natureza do homem e a do seu ambiente necessario, a sociedade, é preparar os elementos indispensaveis para a formação de uma theoria juridica, verdadeira e desenvolvida, para determinar com exactidão o conjuncto organico das condições de vida e desenvolvimento do individuo e da sociedade, que podem ser garantidas pela força coercitiva do Estado, e convem que o sejam. A' falta de noções verdadeiras da anthropologia se deve, por exemplo, o extremo rigor com que outr'ora se puniam delictos imaginarios - como a magia, ao mesmo tempo que nenhuma lei, nenhum regulamento de hygiene, evitava as innumeras formas de contagio, de que hoje estão preservados os homens nos paizes cultos. Os crimes contra a vida e a integridade physica, perpetrados pelos depositarios do poder, nas nações sujeitas ao despotismo, 
não se repetem nas sociedades livres e adeantadas, graças a uma verdadeira comprehensạ̃o da egualdade anthropologica. No proprio direito internacional $o$ progresso dos estudos anthropologicos, espancando os preconceitos sobre a inferioridade de umas raças e sub-raças em relação ás outras, vae contribuindo manifestamente para o respeito da vida humana. Foram a mesma noção da egualdade anthropologica, tão difficilmente propagada e que tantos seculos gastou para se incutir no espirito da maioria dos homens, e a demonstração, pela economia politica, da maior productividade do trabalho livre, que, pondo em perfeita evidencia a absoluta ausencia de fundamento da escravidão, extinguiram esse instituto juridico, que durante tanto tempo coexistiu ao lado da mais elevada moral empirica, a do christianismo. Ṕara combater o preconceito, o hediondo e feroz preconceito, que é o maior inimigo do aperfeiçoamento juridico, a mais efficaz de todas as armas é a divulgação dos conhecimentcs anthropologicos e sociaes.

Quando os progressos da anthropologia, da sociologia, tão incipiente ainda, e das sciencias sociaes particulares, permittirem ao homem formar conceitos verdadeiros, certos e precisos, ácerca das necessidades da natureza do individuo e da sociedade, novos e amplos horizontes se abrirão á sciencia juridica. Então, será possivel substituir em vasta escala o processo inductivo, hoje o mais applicado (e muito deficientemente em consequencia de estar excluida dos estudos sociaes a experimentação, reputada perigosa para a sociedade), pelo processo deductivo, baseado nas verdades geraes da anthropologia e das sciencias sociaes.

O progresso de uma sciencia, é isto hoje uma verdade vulgar, mede-se pela extensão do methodo deductivo. A mais adeantada de todas, a mathematica, quasi sómente deduz. De alguns principios cer- 


\section{- $54-$}

tos extrae todas as verdades, que lhe formam o vasto dominio. Nos casos em que não é possivel applicar tão frequentemente a deducção, combinam-se ao menos os dois processos logicos. Um exemplo classico da combinação dos dois methodos, que bem póde considerar-se o ideal da methodologia de todas as sciencias, é o que nos dá a astronomia com o descobrimento do planeta - Neptuno: quasi ao mesmo tempo que Leverrier em França e Adams na Inglaterra, pelo méro raciocinio deductivo, tendo como ponto de partida verdades geraes, affirmavam a existencia desse planeta em determinado ponto do céu, Galle em Berlim, pela observação telescopica, o apontava no sitio indicado pela deducção.

As sciencias que hão de permittir ao jurista a formação de uma doutrina verdadeira sobre as condições de vida e desenvolvimento do individuo $e$ da sociedade, que o Estado póde garantir, são evidentemente as que têm por missão estudar a natureza humana e a da sociedade, a anthropologia, a sociologia e as sciencias sociaes particulares.

Que abysmo entre a concepção scientifica do direito e as velhas doutrinas, que o assentavam no facto sobrenatural da revelação e nas idéas racionaes, interpretadas ao sabor de cada espirito, e que absolutamente nada nos diziam!

Pedro Lessa. 